\title{
ONE YEAR RANDOMISED CONTROLLED TRIAL TO COMPARE THE EFFECTIVENESS OF TRICLOSAN- COATED PDS PLUS VERSUS UNCOATED PDS SUTURES IN PREVENTION OF SURGICAL SITE INFECTIONS AFTER MONOLAYER CLOSURE IN OPEN ABDOMINAL SURGERIES
}

\author{
Ramesh S. Koujalagi ${ }^{1}$, S. S. K. Kanth Kavipurapu²
}

${ }^{1}$ Associate Professor, Department of General Surgery, Jawaharlal Nehru Medical College, Belgaum, Karnataka, India. ${ }_{2}^{2}$ Postgraduate Student, Department of General Surgery, Jawaharlal Nehru Medical College, Belgaum, Karnataka, India.

\section{ABSTRACT}

\section{BACKGROUND}

Surgical site infections remain one of the most frequent complications in open abdominal surgery. This study compared the effectiveness of Triclosan-coated PDS Plus and non-coated PDS II after monolayer abdominal fascia closure in preventing SSI in open abdominal surgeries.

\section{MATERIALS AND METHODS}

The randomised controlled trial was conducted in the Department of General Surgery, KLES Dr. Prabhakar Kore Hospital and Medical Research Centre, Belgaum for a period of one year from January 2014 to December 2014 were studied. A total of 60 patients undergoing open abdominal surgeries (clean contaminated) were enrolled. These patients were divided into two groups of 30 each based on suture material used to close the abdominal fascia in monolayer as Group A (PDS II sutures) and Group B (PDS plus sutures).

\section{RESULTS}

Most of the patients were males in Group A and B (63.33\%) with males to female ratio of 1.72:1 ( $p=1.000)$. The mean age in Group A and Group B was comparable (39.90 \pm 11.67 vs $41.67 \pm 16.08$ years; $p=0.687)$. Other pre-intervention characteristics were comparable $(\mathrm{p}>0.050)$. On post-operative day two, discharged $(63.33 \%$ vs $70 \%)$ positive culture $(81.82 \%$ vs $77.78 \%)$ were comparable. The commonest organism in Group A was Escherichia coli and pseudomonas aeruginosa (27.27\%) and in Group B, pseudomonas aeruginosa was the commonest organism $(22.22 \%)(p>0.050)$. Similar trend was noted on day six and ten. Pain, local tenderness, redness, raised local temperature, fever were comparable in Group A and Group B on day two and ten ( $p>0.050$ ). The surgical site infections were present in $43.33 \%$ of the patients in Group A compared to 30\% of the patients in Group B $(\mathrm{p}=0.284)$.

\section{CONCLUSION}

Abdominal fascia closure with Triclosan-coated PDS Plus sutures is as effective as non-coated PDS sutures after monolayer closure in clean contaminated open abdominal surgeries in the prevention of surgical site infections.

\section{KEYWORDS}

Surgical Site Infections; Sutures; Triclosan.

HOW TO CITE THIS ARTICLE: Koujalagi RS, Kavipurapu SSKK. One year randomised controlled trial to compare the effectiveness of triclosan-coated PDS plus versus uncoated PDS sutures in prevention of surgical site infections after monolayer closure in open abdominal surgeries. J. Evolution Med. Dent. Sci. 2017;6(44):3432-3438, DOI: 10.14260/Jemds/2017/744

\section{BACKGROUND \\ Post-operative wound infection is considered as surgeon's nightmare. ${ }^{1}$ Surgical Site Infections (SSIs) are infections of tissues, organs or spaces exposed by surgeons during performance of an invasive procedure and remain one of the most frequent complications in open abdominal surgery. This complication while seemingly infrequent adds to the morbidity and delays wound healing. ${ }^{2}$ \\ It was not until late 1860s, after Joseph Lister introduced the principles of antisepsis, that post-operative infectious}

Financial or Other, Competing Interest: None.

Submission 14-04-2017, Peer Review 19-05-2017,

Acceptance 25-05-2017, Published 01-06-2017.

Corresponding Author:

Dr. Ramesh S. Koujalagi,

Plot No. 44, Scheme No. 56,

Kumarswamy Layout, Bauxite Road,

Belgaum - 590 010,

Karnataka, India.

E-mail: drrameshkoujalagi@gmail.com

DOI: $10.14260 /$ jemds/2017/744 morbidity decreased substantially. ${ }^{3}$ In 1992, the US Centers for Disease Control (CDC) revised its definition of 'wound infection' creating the definition 'Surgical Site Infection' (SSI). The Centers for Disease Control and Prevention (CDC) ${ }^{4}$ has classified Surgical Site Infections (SSI) into superficial or deep or organ/space SSIs occurring within 30 days of surgery.

An estimated 2,342 million surgeries were performed annually resulting in more than 7 million complications worldwide. 5 According to the CDC Healthcare-Associated Infection (HAI) prevalence survey, there were an estimated 157,500 surgical site infections associated with inpatient surgeries in 2011.6 NHSN data for 2006 - 2008 (16,147 SSIs following 849,659 operative procedures) showed an overall SSI rate of $1.9 \% .^{7}$ The incidence of SSIs with regard to abdominal surgical sites and operating conditions is between 1.5 to $3.7 \%$ for clean wounds, 3 to $4 \%$ for clean-contaminated wounds, $8.5 \%$ for contaminated wounds and as high as 28 to $40 \%$ for dirty-infected wounds. In India, various studies have reported high SSI incidence rates. ${ }^{8}$

Surgical site infection is a dangerous condition and a heavy burden on the patient and social health system. These 
infections lengthen hospital stay for an average up to seven days. Potential sources of infection are the patient (especially contamination by alimentary tract bacteria), hospital environment, food, other patients, staff, infected surgical instruments, dressings and even drugs and injections. ${ }^{9}$

SSIs are associated with a two-fold increased relative risk of in-hospital mortality ${ }^{10}$ and over one-third of postoperative deaths in patients with SSIs are attributable to the infection. ${ }^{11}$ Furthermore, several studies have shown an increase in the length of hospital stay between $6-24$ days. ${ }^{12}$ The resulting direct costs have to be added to the indirect costs resulting in substantial expenses to the healthcare system and the society. ${ }^{13}$

The causes of SSIs are multifactorial, but crucially SSIs are preventable. ${ }^{14}$ Patient-related factors such as comorbidities (e.g. Diabetes Mellitus) or lifestyle habits (e.g. Smoking) have to be taken into account, but are difficult to change once an intervention is needed. Therefore, further efforts on the surgeon's side are required to reduce the frequency of SSI. 15

A wide variety of aerobic and anaerobic species of bacteria may be present, either single or in combination. The most frequent pathogens causing postoperative SSIs following abdominal surgery are endogenous pathogens from the skin or gastrointestinal tract. ${ }^{3}$

Although, there are other methods for mechanical wound closure such as staples, tape and adhesives, sutures are the most widely used materials in wound closure. Surgical site infections are also related to suture. ${ }^{9} \mathrm{~A}$ suture is a biomaterial device, natural or synthetic, used to approximate tissues together following separation by surgery or trauma. It can also be used to denote the method used for mechanical wound closure. 16

One important factor in the development of SSI is bacterial colonisation of suture material, especially on braided sutures and around suture knots. ${ }^{17}$ Microorganisms colonise the suture as it is passed through human tissue in the surgical wound, which then forms a "biofilm" that confers immunity from antimicrobial treatment and the immune system. ${ }^{18}$ Once a biofilm is established, it is difficult to remove the organism and this potentiates the risk of developing an SSI. Hence, the idea of using sutures with antibacterial properties was a logical extension to minimise this risk.

Triclosan (2, 2, 4'-trichloro-2'-hydroxyphenyl ether) is synthetic broad-spectrum anti-microbial agent present in the market for more than 40 years, mainly in the personal care or consumer products. Currently, Triclosan is found in variety of skin care or personal care products such as hand soaps, shower gels, mouth washes, deodorant soaps, toothpastes, etc. Use of Triclosan in healthcare industry started in 1972, in surgical scrubs. It has also been used in other medical products such as hand scrubs, skin antiseptics, ointments, impregnated/coated catheters and sutures. ${ }^{19}$

However, there is scarcity of the literature on the role of Triclosan-coated PDS plus suture in reducing surgical site infections in settings of open abdominal surgeries. Hence, the present study was planned to compare the effectiveness of Triclosan-coated PDS plus for abdominal fascia closure in preventing SSI compared to non-coated PDS sutures after monolayer closure in open abdominal surgeries.

\section{MATERIALS AND METHODS}

This randomised controlled trial was carried out in the Department of Surgery of a tertiary care centre situated in North Karnataka from January 2014 to December 2014. Based on the previous literature, considering P1 as $11.3 \%$ and the P2 as $6.4 \%$ and the sample size calculated was 305 per group. However, as it was not feasible in the current setting, the sample size was taken as 60 patients undergoing open abdominal surgeries (clean contaminated) divided into two groups of 30 each of either sex with age more than 14 years were included in the study. Patient's diabetes mellitus or immunodeficiency, received systemic antibiotics within 2 weeks of proposed surgery and contaminated and dirty cases were excluded from the study. Prior to the commencement, the Ethical Clearance was obtained from the Institutional Ethics Committee. The selected patients were briefed about the nature of study and a written informed consent was obtained prior to the enrolment.

The selected patients were briefed about the nature of the study and a written informed consent was obtained. Demographic data like sex and age were collected along with relevant history. A thorough clinical examination was done and the findings were recorded on predesigned and pretested proforma. The present study did not require specific investigations. However, routine investigations required for the surgical fitness including complete blood count, blood urea, serum creatinine, chest x-ray and echocardiography were done.

Based on the wound closure technique, patients were randomised into two groups of 30 each by Opaque Envelope Method as Group A (Primary fascial closure with PDS II sutures) and Group B (Primary fascial closure with PDS plus sutures).

In both the groups, shaving of the abdomen from nipple to mid-thigh prior to surgery was done. On the operation table, the abdomen was cleaned with povidone iodine and spirit. Injection ciprofloxacin $100 \mathrm{~mL}$ IV and Inj. metronidazole 100 mL IV were given prior to skin incision. All the patients had standard analgesic and antibiotics protocol.

Patients in both the groups underwent open abdominal surgeries using similar instruments and accepted general principles of surgery. The closure of wound was done in monolayer. Patients in Group A underwent primary fascial closure with PDS II sutures. Patients in Group B underwent primary fascial closure with PDS plus sutures. The patients were postoperatively medicated with Inj. Ciprofloxacin 100 $\mathrm{mL}$ IV twice daily and Inj. metronidazole $100 \mathrm{~mL}$ thrice daily and if indicated and were changed to higher antibiotics accordingly. Patients were followed on postoperative day 2, 6 and 10.

Patients were evaluated for discharge/pus from the wound, if any during post-operative followup on postoperative day 2, 6 and 10. In cases with presence of discharge/pus, samples were collected and sent for culture and sensitivity. Also, the wound was inspected for local tenderness, redness and raised local temperature. Further patients were also evaluated for pain and fever. The assessment of pain was subjective.

The endpoint of the study was presence or absence of 'Postoperative surgical site infection.' An incisional surgical site infection was considered to be positive if surgical wound drained purulent material or if the surgeon judges it to be 
infected and opens it. The surgical wound infection was defined according to US Center for Disease Control and Prevention (CDC) as SSI. ${ }^{20}$

\section{Statistical Analysis}

The data was tabulated on Microsoft Excel spread sheet. The data was analysed using SPSS version 20.0. Categorical data was expressed as rates, ratios and percentages and continuous data was expressed as mean \pm SD. Categorical data was compared using Chi-square test or Fisher's exact test and continuous data was compared using independent sample ' $\mathrm{t}$ ' test. A probability value of $\leq 0.050$ at $95 \%$ confidence interval was considered as statistically significant.

\section{RESULTS}

In the present study, $63.33 \%$ of the patients in Group A and Group B were males and male-to-female ratio was 1.72:1 in both the groups. $50 \%$ of the patients in Group A were aged $\leq$ 30 years, while in Group B 33.33\% of the patients were aged 31 to 40 years. However, this difference was statistically not significant $(\mathrm{p}=0.262)$. The mean age in Group A and Group B was comparable $(39.90 \pm 17.67$ years vs $41.67 \pm 16.08$ years; $\mathrm{p}=0.687$ ). $40 \%$ of the patients in Group A presented with fever compared to $23.33 \%$ in Group B. However, this difference was statistically not significant $(p=0.165)$. The features of vomiting at presentation were noted in $43.33 \%$ of the patients in Group A compared to $63.33 \%$ in Group B, but the difference was statistically not significant $(p=0.121)$. Abdominal examination revealed tenderness in $60 \%$ of the patients who were in Group A and 53.33\% in Group B $(\mathrm{p}=0.602)$. The mean pulse rate, respiratory rate, systolic and diastolic blood pressure were comparable in Group A and B ( $p>0.050$ ). Table 1 shows distribution of patients according to the type of surgery and it was observed that comparable in Group A and B ( $\mathrm{p}=0.172$ ) Table 2 shows wound examination findings on day two. It was observed that pain, local tenderness, redness, raised local temperature, discharge and fever were present in 56.67\%, 53.33\%, 40\%, 40\%, 36.67\% and $26.67 \%$ of the patients in Group A compared to $40 \%$, $36.67 \%, 33.33 \%, 33.33 \%, 30 \%$ and $20 \%$ in Group B respectively. However, the differences observed in Group A and B were statistically not significant $(\mathrm{p}>0.050)$. On day two, positive culture was noted in $81.82 \%$ of the patients who had discharge/pus in Group A compared to $77.78 \%$ in Group B. However, the differences observed in Group A and B were statistically not significant $(p=1.000)$. Pseudomonas aeruginosa was the commonest organism isolated in $27.27 \%$ of the patients in Group A and 22.22\% in Group B ( $p=0.935)$ (Table 3).

On day six most of the patients had discharge in Group A (43.33\%), while in Group B most of the patients reported pain $(30 \%)$. However, the wound observations made on day six did not vary significantly in Group A and B ( $p>0.050)$ (Table 4). Wound culture was positive in $46.15 \%$ of the patients who had discharge/pus in Group A compared to $62.50 \%$ in Group B ( $p=0.659)$. Pseudomonas aeruginosa was the commonest organism isolated in Group A (23.08\%) and B (25\%) $(\mathrm{p}=0.334)$ (Table 5).

Wound examination on day ten revealed discharge in $16.67 \%$ of the patients in Group A, and redness in $10 \%$ of the patients in Group B. However, the wound characteristics on day ten were comparable in Group A and B ( $p>0.050)$
(Table 5). In patients with presence of discharge/pus on day ten, wound culture was positive in $40 \%$ of the patients among the patients of Group A compared to $50 \%$ in Group B. Wound culture revealed $20 \%$ of the patients with MRSA in Group A compared to $50 \%$ in Group B $(p=0.671)$ (Table 7). The surgical site infections were present in $43.33 \%$ of the patients in Group A and 30\% of the patients in Group B. However, this difference was statistically not significant $(p=0.284)$ (Graph 1).

\begin{tabular}{|c|c|c|c|c|}
\hline \multirow{2}{*}{ Type of Surgery } & \multicolumn{2}{|c|}{ Group A $(n=30)$} & \multicolumn{2}{|c|}{ Group B (n=30) } \\
\hline & No. & $\%$ & No. & $\%$ \\
\hline $\begin{array}{c}\text { Small bowel resection } \\
\text { and anastomosis }\end{array}$ & 8 & 26.67 & 8 & 26.67 \\
\hline Appendectomy & 7 & 23.33 & 3 & 10.00 \\
\hline Splenectomy & 3 & 10.00 & 5 & 16.67 \\
\hline Right hemicolectomy & 4 & 13.33 & 2 & 6.67 \\
\hline Gastrojejunostomy & 0 & 0.00 & 3 & 10.00 \\
\hline Ileostomy & 3 & 10.00 & 0 & 0.00 \\
\hline Pancreaticojejunostomy & 2 & 6.67 & 1 & 3.33 \\
\hline Feeding jejunostomy & 0 & 0.00 & 2 & 6.67 \\
\hline Fundoplication & 0 & 0.00 & 2 & 6.67 \\
\hline Diversion colostomy & 1 & 3.33 & 1 & 3.33 \\
\hline $\begin{array}{c}\text { Abdominoperineal } \\
\text { resection }\end{array}$ & 0 & 0.00 & 2 & 6.67 \\
\hline Cystogastrostomy & 2 & 6.67 & 1 & 3.33 \\
\hline Total & 30 & 100.00 & 30 & 100.00 \\
\hline
\end{tabular}

$\mathrm{P}=0.172$

\begin{tabular}{|c|c|c|c|c|c|c|}
\hline \multirow[t]{2}{*}{ Findings } & \multirow[t]{2}{*}{ Findings } & \multicolumn{2}{|c|}{$\begin{array}{c}\text { Group A } \\
(n=30)\end{array}$} & \multicolumn{2}{|c|}{$\begin{array}{c}\text { Group B } \\
(n=30)\end{array}$} & \multirow{2}{*}{$\begin{array}{c}P \\
\text { value }\end{array}$} \\
\hline & & No & $\%$ & No & $\%$ & \\
\hline \multirow[t]{3}{*}{ Pain } & Absent & 13 & \begin{tabular}{|l|}
43.33 \\
\end{tabular} & 18 & 60.00 & 0.196 \\
\hline & Present & 17 & \begin{tabular}{|l|}
56.67 \\
\end{tabular} & 12 & 40.00 & \\
\hline & Total & 30 & 100.00 & 30 & 100.00 & \\
\hline \multirow[t]{3}{*}{\begin{tabular}{|c|} 
Local \\
Tenderness \\
\end{tabular}} & Absent & 14 & 46.67 & 19 & 63.33 & 0.194 \\
\hline & Present & 16 & 53.33 & 11 & 36.67 & \\
\hline & Total & 30 & 100.00 & 30 & 100.00 & \\
\hline \multirow[t]{3}{*}{ Redness } & Absent & 18 & 60.00 & 20 & 66.67 & 0.592 \\
\hline & Present & 12 & 40.00 & 10 & 33.33 & \\
\hline & Total & 30 & 100.00 & 30 & 100.00 & \\
\hline Raised Local & Absent & 18 & \begin{tabular}{|l|}
60.00 \\
\end{tabular} & 20 & 66.67 & 0.592 \\
\hline \multirow[t]{2}{*}{ Temperature } & Present & 12 & 40.00 & 10 & 33.33 & \\
\hline & Total & 30 & 100.00 & 30 & 100.00 & \\
\hline \multirow[t]{3}{*}{ Discharge } & Absent & 19 & 63.33 & 21 & 70.00 & 0.584 \\
\hline & Present & 11 & 36.67 & 9 & 30.00 & \\
\hline & Total & 30 & 100.00 & 30 & 100.00 & \\
\hline \multirow[t]{3}{*}{ Fever } & Absent & 22 & 73.33 & 24 & 80.00 & 0.542 \\
\hline & Present & 8 & 26.67 & 6 & 20.00 & \\
\hline & Total & 30 & 100.00 & 30 & 100.00 & \\
\hline
\end{tabular}

\begin{tabular}{|c|c|c|c|c|c|c|}
\hline \multirow{2}{*}{ Findings } & \multirow{2}{*}{ Findings } & \multicolumn{2}{|c|}{$\begin{array}{c}\text { Group A } \\
\text { (n=11) }\end{array}$} & \multicolumn{2}{c|}{$\begin{array}{c}\text { Group B } \\
\text { (n=9) }\end{array}$} & \multirow{2}{*}{ P } \\
\cline { 3 - 7 } & & No & $\mathbf{9}$ & No & \% & \\
\hline Culture & Negative & 2 & 18.18 & 2 & 22.22 & 1.000 \\
\hline & Positive & 9 & 81.82 & 7 & 77.78 & \\
\hline & Total & $\mathbf{1 1}$ & $\mathbf{1 0 0 . 0 0}$ & $\mathbf{9}$ & $\mathbf{1 0 0 . 0 0}$ & \\
\hline Organism & $\begin{array}{c}\text { Coagulase-neg } \\
\text { staphylococci }\end{array}$ & 0 & 0.00 & 1 & 11.11 & 0.935 \\
\hline & E. coli & 3 & 27.27 & 1 & 11.11 & \\
\hline & Enterobacter sp. & 0 & 0.00 & 1 & 11.11 & \\
\hline & $\begin{array}{c}\text { Pseudomonas } \\
\text { aeruginosa }\end{array}$ & 3 & 27.27 & 2 & 22.22 & \\
\hline
\end{tabular}




\begin{tabular}{|c|c|c|c|c|c|c|}
\hline $\begin{array}{c}\text { Staphylococcus } \\
\text { aureus }\end{array}$ & 2 & 18.18 & 1 & 11.11 & \\
\hline $\begin{array}{c}\text { Staphylococcus } \\
\text { epidermidis }\end{array}$ & 1 & 9.09 & 1 & 11.11 & \\
\hline No growth & 2 & 18.18 & 2 & 22.22 & \\
\hline & Total & $\mathbf{1 1}$ & $\mathbf{1 0 0 . 0 0}$ & $\mathbf{9}$ & $\mathbf{1 0 0 . 0 0}$ & \\
\hline \\
Table 3. Comparison of Wound Culture \\
and Organisms on Day Two
\end{tabular}

\begin{tabular}{|c|c|c|c|c|c|c|}
\hline \multirow[t]{2}{*}{ Findings } & \multirow{2}{*}{ Findings } & \multicolumn{2}{|c|}{$\begin{array}{c}\text { Group A } \\
(n=30)\end{array}$} & \multicolumn{2}{|c|}{$\begin{array}{c}\text { Group B } \\
(n=30)\end{array}$} & \multirow{2}{*}{$\begin{array}{c}P \\
\text { value }\end{array}$} \\
\hline & & No & $\%$ & No & $\%$ & \\
\hline \multirow[t]{3}{*}{ Discharge } & Absent & 17 & 56.67 & 22 & 73.33 & 0.176 \\
\hline & Present & 13 & 43.33 & 8 & 26.67 & \\
\hline & Total & 30 & 100.00 & 30 & 100.00 & \\
\hline Local & Absent & 18 & 60.00 & 23 & 76.67 & 0.165 \\
\hline \multirow[t]{2}{*}{\begin{tabular}{|l|} 
Tenderness \\
\end{tabular}} & Present & 12 & 40.00 & 7 & 23.33 & \\
\hline & Total & 30 & 100.00 & 30 & 100.00 & \\
\hline \multirow[t]{3}{*}{ Pain } & Absent & 19 & 63.33 & 21 & 70.00 & 0.584 \\
\hline & Present & 11 & 36.67 & 9 & 30.00 & \\
\hline & Total & 30 & 100.00 & 30 & 100.00 & \\
\hline \multirow[t]{3}{*}{ Redness } & Absent & 20 & 66.67 & 22 & 73.33 & 0.573 \\
\hline & Present & 10 & 33.33 & 8 & 26.67 & \\
\hline & Total & 30 & 100.00 & 30 & 100.00 & \\
\hline \begin{tabular}{|l|} 
Raised Local \\
\end{tabular} & Absent & 21 & 70.00 & 24 & 80.00 & 0.371 \\
\hline \multirow[t]{2}{*}{ Temperature } & Present & 9 & 30.00 & 6 & 20.00 & \\
\hline & Total & 30 & 100.00 & 30 & 100.00 & \\
\hline \multirow[t]{3}{*}{ Fever } & Absent & 22 & 73.33 & 28 & 93.33 & 0.038 \\
\hline & Present & 8 & 26.67 & 2 & 6.67 & \\
\hline & Total & 30 & 100.00 & 30 & 100.00 & \\
\hline
\end{tabular}

\begin{tabular}{|c|c|c|c|c|c|c|}
\hline \multirow[t]{2}{*}{ Findings } & \multirow[t]{2}{*}{ Findings } & \multicolumn{2}{|c|}{$\begin{array}{c}\text { Group A } \\
(n=13)\end{array}$} & \multicolumn{2}{|c|}{$\begin{array}{c}\text { Group B } \\
(n=8)\end{array}$} & \multirow{2}{*}{$\begin{array}{c}\mathbf{P} \\
\text { value }\end{array}$} \\
\hline & & No & $\%$ & No & $\%$ & \\
\hline \multirow[t]{3}{*}{ Culture } & Negative & 7 & 53.85 & 3 & 37.50 & 0.659 \\
\hline & Positive & 6 & 46.15 & 5 & 62.50 & \\
\hline & Total & 13 & 100.00 & 8 & 100.00 & \\
\hline \multirow[t]{6}{*}{ Organism } & Enterobacter sp. & 2 & 15.38 & 0 & 0.00 & 0.334 \\
\hline & $\begin{array}{l}\text { Pseudomonas } \\
\text { aeruginosa }\end{array}$ & 3 & 23.08 & 2 & 25.00 & \\
\hline & $\begin{array}{c}\text { Staphylococcus } \\
\text { aureus }\end{array}$ & 1 & 7.69 & 2 & 25.00 & \\
\hline & $\begin{array}{c}\text { Staphylococcus } \\
\text { epidermidis }\end{array}$ & 0 & 0.00 & 1 & 12.50 & \\
\hline & No growth & 7 & 53.85 & 3 & 37.50 & \\
\hline & Total & 13 & 100.00 & 8 & 100.00 & \\
\hline \multicolumn{7}{|c|}{$\begin{array}{c}\text { Table 5. Comparison of Wound Culture and Organism on } \\
\text { Day Six }\end{array}$} \\
\hline
\end{tabular}

\begin{tabular}{|c|c|c|c|c|c|c|}
\hline \multirow[t]{2}{*}{ Variables } & \multirow[t]{2}{*}{ Findings } & \multicolumn{2}{|c|}{$\begin{array}{c}\text { Group A } \\
(n=30)\end{array}$} & \multicolumn{2}{|c|}{$\begin{array}{c}\text { Group B } \\
(n=30)\end{array}$} & \multirow{2}{*}{$\begin{array}{c}p \\
\text { value }\end{array}$} \\
\hline & & No & $\%$ & No & $\%$ & \\
\hline \multirow[t]{3}{*}{ Discharge } & Absent & 25 & 83.33 & 28 & \begin{tabular}{|c|}
93.33 \\
\end{tabular} & 0.212 \\
\hline & Present & 5 & 16.67 & 2 & 6.67 & \\
\hline & Total & 30 & 100.00 & 30 & 100.00 & \\
\hline \multirow[t]{3}{*}{ Pain } & Absent & 25 & 83.33 & 28 & \begin{tabular}{|l|}
93.33 \\
\end{tabular} & 0.212 \\
\hline & Present & 5 & 16.67 & 2 & 6.67 & \\
\hline & Total & 30 & 100.00 & 30 & 100.00 & \\
\hline \multirow[t]{3}{*}{$\begin{array}{c}\text { Local } \\
\text { Tenderness }\end{array}$} & Absent & 26 & 86.67 & 29 & 96.67 & 0.177 \\
\hline & Present & 4 & 13.33 & 1 & 3.33 & \\
\hline & Total & 30 & 100.00 & 30 & 100.00 & \\
\hline \multirow[t]{3}{*}{ Fever } & Absent & 27 & 90.00 & 30 & 100.00 & 0.119 \\
\hline & Present & 3 & 10.00 & 0 & 0.00 & \\
\hline & Total & 30 & 100.00 & 30 & 100.00 & \\
\hline \multirow[t]{3}{*}{ Redness } & Absent & 28 & 93.33 & 27 & 90.00 & 0.500 \\
\hline & Present & 2 & 6.67 & 3 & \begin{tabular}{|l|}
10.00 \\
\end{tabular} & \\
\hline & Total & 30 & 100.00 & 30 & 100.00 & \\
\hline
\end{tabular}

\begin{tabular}{|c|c|c|c|c|c|c|}
\hline Raised Local & Absent & 28 & 93.33 & 29 & 96.67 & 0.500 \\
\hline Temperature & Present & 2 & 6.67 & 1 & 3.33 & \\
\hline \multicolumn{1}{|c|}{ Total } & $\mathbf{3 0}$ & $\mathbf{1 0 0 . 0 0}$ & $\mathbf{3 0}$ & $\mathbf{1 0 0 . 0 0}$ & \\
\hline
\end{tabular}

\begin{tabular}{|c|c|c|c|c|c|c|}
\hline \multirow[t]{2}{*}{ Findings } & \multirow[t]{2}{*}{ Findings } & \multicolumn{2}{|c|}{$\begin{array}{c}\text { Group A } \\
(n=5)\end{array}$} & \multicolumn{2}{|c|}{$\begin{array}{c}\text { Group B } \\
(n=2)\end{array}$} & \multirow{2}{*}{$\begin{array}{c}P \\
\text { value }\end{array}$} \\
\hline & & No & $\%$ & No & $\%$ & \\
\hline \multirow[t]{3}{*}{ Culture } & Negative & 3 & 60.00 & 1 & 50.00 & 1.000 \\
\hline & Positive & 2 & 40.00 & 1 & 50.00 & \\
\hline & Total & 5 & 100.00 & 2 & 100.00 & \\
\hline \multirow[t]{4}{*}{ Organism } & MRSA & 1 & 20.00 & 1 & 50.00 & 0.671 \\
\hline & $\begin{array}{c}\text { Pseudomonas } \\
\text { aeruginosa }\end{array}$ & 1 & 20.00 & 0 & 0.00 & \\
\hline & No growth & 3 & 60.00 & 1 & 50.00 & \\
\hline & Total & 5 & 100.00 & 2 & 100.00 & \\
\hline & $\begin{array}{r}\text { 7. Comp } \\
\text { Org }\end{array}$ & & $\begin{array}{l}f W o \\
n D a\end{array}$ & & e and & \\
\hline
\end{tabular}

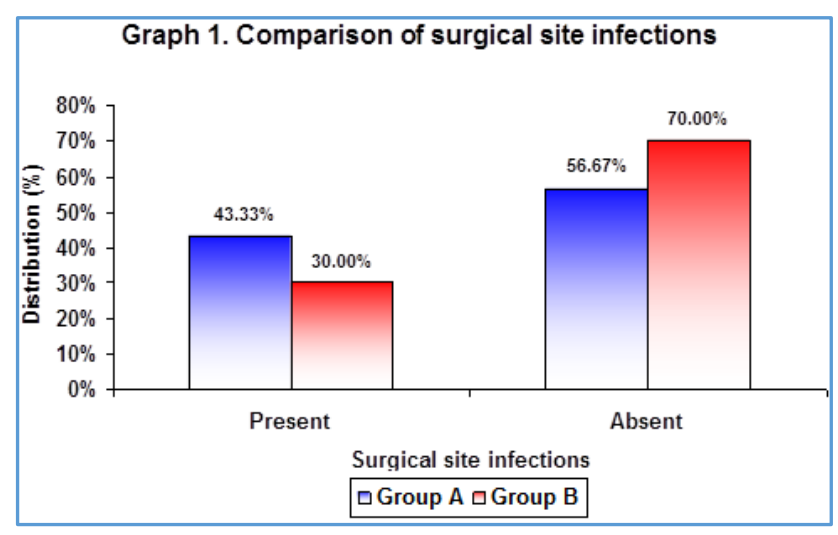

$\mathrm{P}=0.284$

\section{DISCUSSION}

In the present study, slight male preponderance was noted as male-to-female ratio in Group A and Group B was 1.72:1 with $63.33 \%$ of the patients each in both the groups. However, the sex distribution pattern in Group A and Group B were comparable $(p=0.262)$. A prospective randomised controlled trial by Justinger et $\mathrm{al}^{21}$ to evaluate the role of PDS II and PDS plus reported similar sex distribution pattern.

In this study, nearly half of the study population (50\%) in Group A was aged $\leq 30$ years, whereas $33.33 \%$ of the patients in Group B were aged 31 to 40 years. The mean age in Group A was noted as $39.90 \pm 11.67$ years and in Group B it was $41.67 \pm 16.08$ years. However, this difference was statistically not significant suggesting that age distribution in the study population in Group A and B was almost equal ( $p$ > 0.050). However, the mean age observed in the present study was low compared to a study by Justinger et al. ${ }^{21}$

In this study, the clinical presentation including fever $(\mathrm{p}=$ $0.165)$ and vomiting $(p=0.121)$ were comparable in patients with Group A and Group B. On systemic examination, the mean pulse rate, respiratory rate, systolic and diastolic blood pressure in Group A and Group B were comparable ( $p>0.050)$. Abdominal examination revealed tenderness in most of the patients, which was also comparable in Group A and Group B ( $p=0.602)$. Furthermore, small bowel resection was the commonest surgery which was performed in $26.67 \%$ of the patients each in Group A and Group B (p=0.172).

These findings suggest that demographic, clinical and surgical characteristics of the patient in Group A and Group B 
did differ significantly $(\mathrm{p}>0.050)$ ruling out the possible bias in the results.

In the present study wound examination of day two revealed pain in $56.67 \%$, local tenderness in $53.33 \%$, redness and raised local temperature in $40 \%$ each, discharge in $36.67 \%$ and fever in $26.67 \%$ of the patients in Group A. The frequency of these features was slightly low in patients with Group B, that is pain was present in $40 \%$, local tenderness in $36.67 \%$, redness and raised local temperature in $33.33 \%$ each, discharge in $30 \%$ and fever in $20 \%$. However, the difference observed between Group A and Group B pertaining to the feature of pain, local tenderness, redness, raised local temperature, discharge and fever was statistically not significant $(\mathrm{p}=0.050)$.

During the examination on day six, $43.33 \%$ of the patients in Group A had discharge as compared to $26.67 \%$ of the patients in Group B $(p=0.176)$. In Group B, most of the patients, that is $30 \%$ had pain compared to $36.67 \%$ in Group $A(p=0.584)$. On day ten, discharge was present in $16.67 \%$ of the patients in Group A compared to $6.67 \%$ in Group B ( $p=$ 0.212 ). In Group B, redness was noted in $10 \%$ of the patients compared to $6.67 \%$ of the patients in Group B (p=0.500).

These findings suggest that Group B where patients underwent primary fascial closure with PDS plus Triclosancoated sutures resulted in lower rates of pain, local tenderness, redness, raised local temperature, discharge and fever compared to primary fascial closure with PDS II sutures, but as the differences observed were statistically not significant $(p>0.050)$.

In the present study among the patients with discharge/pus, rate of positive wound culture was $81.82 \%$ among the patients in Group A on day two. This rate of positive wound culture on day six reduced to $46.15 \%$ and $40 \%$ on day ten. Among the patients with Group B, the rate of positive wound culture was $77.78 \%$ on day two which reduced to $62.50 \%$ on day six and $50 \%$. Further, pseudomonas aeruginosa was the commonest isolate in Group A and Group B on day two as well as day six, while MRSA was the commonest organism isolated on day ten. However, the rate of positive wound culture and organism profile in Group A and Group B were comparable ( $p>0.050$ ). These findings suggest that PDS plus Triclosan-coated sutures and PDS II sutures offer similar antimicrobial properties.

In the present study, frequency of surgical site infections was high $(43.33 \%)$ in patients with Group A compared to Group B (30\%), but the difference was statistically not significant $(\mathrm{p}=0.284)$. These findings suggest that PDS plus Triclosan-coated sutures have positive role in reduction of surgical site infection, but not significant compared to PDS II sutures.

Wide range of published studies is available for toxicity profile of Triclosan, antibacterial profile and clinical effectiveness of TCS. However, in contrast to our findings they have reported statistical significant results favouring TCS in reduction of risk of SSIs.

Daoud FC et $\mathrm{al}^{22}$ in 2014 analysed the data from 15 RCTs totalling 4000 patients (TCS $=2323$ ) and NTCS $=2477)$. Use of TCS was associated with a decrease in SSIs in selected patient population $(\mathrm{RR}=0.67 ; \mathrm{P}=0.00053)$, means $33 \%$ reduction in risk of developing SSIs. TCS showed highly statistical significant results in lowering risk of SSI. TCS was effective in clean $(\mathrm{P}=0.001)$, clean-contaminated $(\mathrm{P}=0.010)$ and contaminated incisions $(\mathrm{P}=0.026)$. SLR result was robust to the removal of three RCTs. SLR showed highly statistical significant results favouring TCS in reduction of risk of SSI and robustness of clinical results - relative risk independent of confounding factors.

Edmiston CE et al ${ }^{23}$ in 2013 conducted a meta-analysis in response to recently published systematic reviews and metaanalysis which have suggested about no benefits of antimicrobial-coated suture in reducing the Surgical Site Infections (SSI). Authors have highlighted poor selection of available RCT and low patient numbers for these metaanalyses. The primary endpoint of the systematic review was to determine the ratio of patients who developed an SSI in two comparative groups: closure with TCS versus NTCS sutures. Total 13 RCTs were selected, totalling 3568 patients $(\mathrm{TCS}=1654)$ and NTCS $=1914)$. Use of TCS was associated with a decrease in SSIs in selected patient populations (fixed effect: $\mathrm{RR}=0.734 ; \mathrm{P}=0.005$; random-effect: $\mathrm{RR}=0.693 ; \mathrm{P}=$ 0.011 ), means $27-31 \%$ reduction in risk of developing SSIs.

Wang ZX et al ${ }^{24}$ in 2013 performed meta-analysis with 17 RCTs covering 3720 patients $($ TCS $=1726)$ and NTCS $=1994)$. Results favoured TCS with a pooled RR of $0.70(\mathrm{P}<0.001)$ without statistical heterogeneity ( $\mathrm{P}$ for $\mathrm{Q}$ test $=0.129, \mathrm{I} 2=29$ percent), means TCS provided significant advantage in reducing the rate of SSI by $30 \%$. Subgroup analysis indicates statistical significant results of reduction in SSI by using TCS in adult patients, abdominal surgery and clean or clean contaminated wounds. The advantage of TCS over conventional sutures was consistent regardless of length of followup.

Justinger $\mathrm{C}$ et $\mathrm{al}^{25}$ has published large retrospective study of 2088 patients in mid laparotomy. The results showed the decrease in number of SSIs (TCS: 4.9\%, NTCS: 10.8\%, P < 0.001 ) for abdominal wall closure. However, this analysis of the use of Triclosan-coated sutures in laparotomy previously done by Justinger et al has limitations, few limitations. In the sequential design that was employed over a period of 2 years, per definition internal validity cannot be assumed with certainty. It is not at all unlikely that over this relatively long period of time other factors in the patient's treatment might have changed and remained unrecorded, but may have contributed to the reduction in SSI. Furthermore, with a control of PDS II $\AA$ sutures in history the intervention group received Vicryl plus ${ }^{\circledR}$ sutures, a material different in structure (monofil versus braided) and resorption (210 versus 70 days). Braided and non-braided sutures as well as rapidly absorbable and slowly absorbable ones appear to differ in bacterial adherence and interrupted rapid absorbable sutures increase the risk for development of an incisional hernia substantially according to the INLINE systematic review. ${ }^{21}$

In another prospective comparative study in transverse laparotomy for hepatobiliary resections $(n=839)$, TCS showed significant reduction in SSI compared to NTCS arm (4.3\% vs. $9.2 \%, \mathrm{P}=0.05){ }^{26}$

In spinal surgery, TCS found to be effective in reduction of wound infection $(0.5 \%$ vs. $3.9 \%, p=0.020) .{ }^{27}$

A recent paper on gastric cancer surgery via midline laparotomy also showed the reduction of SSI cases in abdominal wall closure. ${ }^{28}$ 
Other prospective studies in digestive tract surgery, breast cancer surgeries, ${ }^{29}$ abdominal surgeries ${ }^{30}$ and cardiac surgeries (sternal site infections), ${ }^{31}$ TCS was found to be effective in minimising the risk of development of SSI postsurgery.

Even though these study results suggest the use of Triclosan-coated sutures in order to lower the risk for SSIs, two important aspects of Triclosan use in healthcare products should be discussed. First, it has been shown that there is a risk of antimicrobial resistance to Triclosan including its use in topical products (e.g. cosmetics), where resistance to populations of S. aureus has been reported. This must be regarded as a major drawback in the use of Triclosan as resistance to antibacterial substances represent a growing problem in modern medicine. On the other hand, if the use of conventional antibiotics in patients with SSI can be reduced by $40 \%$ with Triclosan-coated sutures, this may balance or outweigh the disadvantages. The second issue is the long degradation time of Triclosan and the potential risk for bioaccumulation in the environment. 21

The findings of the present study showed comparable outcomes among the patients with primary fascial closure using PDS plus Triclosan-coated sutures as well as PDS II sutures in terms of SSIs, antimicrobial properties as well as other characteristics. This can be explained by the several facts. Firstly, the present study was performed on patients undergoing clean contaminated open abdominal surgeries only, while the latter studies have proved the efficacy of PDS plus Triclosan-coated sutures in different settings as a study by Justinger et $\mathrm{al}^{25}$ included only patients with laparotomy. Secondly, the sample size of the present study was small ( $n=30$ each), while other studies included large sample size.

The observations of the present study were similar to the results of Diener MK et al in PROUD trial. ${ }^{32}$ They evaluated effectiveness of Triclosan-coated PDS plus sutures for abdominal wall closure and reported that the occurrence of SSIs did not differ between the PDS plus group (87 [14.8\%] of 587 ) and the PDS II group (96 [16.1\%] of 598; or $0.91,95 \%$ CI $0.66-1.25 ; p=0.64$ ). Serious adverse events also did not differ between the groups 146 of 583 (25.0\%) patients treated with PDS plus had at least one serious adverse event compared with 138 of 602 (22.9\%) patients treated with PDS II; $\mathrm{p}=0.39$ ). PROUD trial concluded that Triclosan-coated PDS plus did not reduce the occurrence of surgical site infection after elective midline laparotomy.

Overall, the results of this study showed Triclosan-coated sutures, that is PDS plus result in lower rate of SSI, but no significant reduction was noted. Hence, innovative, multifactorial strategies need to be developed and assessed in future trials to reduce surgical site infections.

\section{CONCLUSION}

The present study showed that Triclosan-coated PDS plus sutures are as effective as PDS II sutures in reducing surgical site infection among the patients undergoing clean contaminated open abdominal surgeries. Further, Triclosancoated PDS plus for abdominal fascia closure results in lower rate of pain, local tenderness, redness, raised local temperature, discharge and fever compared to primary fascial closure with PDS II sutures, but does not reduce significantly. Also, the antimicrobial resistance pattern of Triclosan-coated PDS plus sutures is comparable with PDS II sutures. Hence, it may be concluded that abdominal fascia closure using Triclosan-coated PDS plus sutures is as effective as non-coated PDS sutures after monolayer closure in clean contaminated open abdominal surgeries.

\section{ACKNOWLEDGEMENT}

The authors would like to thank the Head of the Department, Department of General Surgery, KLES Dr. Prabhakar Kore Hospital and Medical Research Centre, Belgaum for allowing us to utilise the infrastructure and facilities. We also extend our sincere gratitude to our Principal, Jawaharlal Nehru Medical College, for permitting us to conduct this study. Last but not the least, authors would like to thank the nursing staff and patients without whom this work was not possible.

\section{REFERENCES}

[1] Ananthakrishnan AN, Kanungo R, Kumar A, et al. Detection of extended spectrum beta lactamase producers among surgical wound infections and burns patients in JIPMER. Indian J Med Microbiol 2000;18(4):160-5.

[2] Brunicardi CF, Andersen DK. Schwartz's manual of surgery. $9^{\text {th }}$ edn. New York, NY: McGraw-Hill 2010.

[3] Mangram AJ, Horan TC, Pearson ML, et al. The hospital infection control practices advisory committee guideline for prevention of surgical site infection, 1999. Special Report. Infect Control Hosp Epidemiol 1999;20(4):250-78.

[4] Horan TC, Gaynes RP, Martone WJ, et al. CDC definitions of nosocomial surgical site infections, 1992: a modification of CDC definitions of surgical wound infections. Infect Control Hosp Epidemiol 1992;13(10):606-8.

[5] Weiser TG, Regenbogen SE, Thompson KD, et al. An estimation of the global volume of surgery: a modelling strategy based on available data. The Lancet 2008;372(9633):139-44.

[6] Magill SS, Edwards JR, Bamberg W, et al. Multistate point-prevalence survey of health care-associated infections. N Engl J Med 2014;370(13):1198-208.

[7] $\mathrm{Mu} \mathrm{Y,} \mathrm{Edwards} \mathrm{JR,} \mathrm{Horan} \mathrm{TC,} \mathrm{et} \mathrm{al.} \mathrm{Improving} \mathrm{risk-}$ adjusted measures of surgical site infection for the national healthcare safety network. Infect Control Hosp Epidemiol 2011;32(10):970-86.

[8] Prasannagupta. A study of comparison of infection rate among various surgical site infection cases in a tertiary care hospital. Int J Biol Med Res 2013;4(1):2905-9.

[9] Razavi SM, Ibrahimpoor M, Kashani AS, et al. Abdominal surgical site infections: incidence and risk factors at an Iranian teaching hospital. BMC Surg 2005;5:2.

[10] Kirkland KB, Briggs JP, Trivette SL, et al. The impact of surgical-site infections in the 1990s: attributable mortality, excess length of hospitalization, and extra costs. Infect Control Hosp Epidemiol 1999;20(11):725-30. 
[11] Astagneau P, Rioux C, Golliot F, et al. Morbidity and mortality associated with surgical site infections: results from the 1997-1999 INCISO surveillance. J Hosp Infect 2001;48(4):267-74.

[12] Merle V, Germain JM, Chamouni P, et al. Assessment of prolonged hospital stay attributable to surgical site infections using appropriateness evaluation protocol. Am J Infect Control 2000;28(2):109-15.

[13] De Lissovoy G, Fraeman K, Hutchins V, et al. Surgical site infection: incidence and impact on hospital utilization and treatment costs. Am J Infect Control 2009;37(5):387-97.

[14] Chang WK, Srinivasa S, Morton R, et al. Triclosanimpregnated sutures to decrease surgical site infections: systematic review and meta-analysis of randomized trials. Ann Surg 2012;255(5):854-9.

[15] Rodeheaver GT, Kurtz LD, Bellamy WT, et al. Biocidal braided sutures. Arch Surg 1983;118(3):322-7.

[16] Gomez-Alonso A, Garcia-Criado FJ, Parreno-Manchado FC, et al. Study of the efficacy of coated Vicryl plus antibacterial suture (Coated polyglactin 910 suture with triclosan) in two animal models of general surgery. J Infect 2007;54(1):82-8.

[17] Katz S, Izhar M, Mirelman D. Bacterial adherence to surgical sutures. A possible factor in suture induced infection. Ann Surg 1981;194(1):35-41.

[18] Gristina AG, Price JL, Hobgood CD, et al. Bacterial colonization of percutaneous sutures. Surgery 1985;98(1):12-9.

[19] Sewlikar SA, Pillai RS, Mahajan NS, et al. Triclosan coated sutures: an overview of safety and efficacy in reducing risk of surgical site infection. Int Surg J 2015;2(1):1-7.

[20] Lister J. On a new method of treating compound fractures. Lancet 1867;89(2272):326-9,387-9,507-9.

[21] Justinger C, Slotta JE, Ningel S, et al. Surgical-site infection after abdominal wall closure with triclosanimpregnated polydioxanone sutures: results of a randomized clinical pathway facilitated trial. Surgery 2013;154(3):589-95.

[22] Daoud FC, Edmiston CE, Leaper D. Metaanalysis of prevention of surgical site infections following incision closure with triclosan-coated sutures: robustness to new evidence. Surg Infect (Larchmt) 2014;15(3):165-81.
[23] Edmiston CE, Daoud FC, Leaper D. Is there an evidence-based argument for embracing an antimicrobial (triclosan)-coated suture technology to reduce the risk for surgical-site infections? A metaanalysis. Surgery 2014;155(2):362-3.

[24] Wang ZX, Jiang CP, Cao Y, et al. Systematic review and meta-analysis of triclosan-coated sutures for the prevention of surgical-site infection. $\mathrm{Br} \mathrm{J}$ Surg 2013;100(4):465-73.

[25] Justinger C, Moussavian MR, Schlueter C, et al. Antibacterial [corrected] coating of abdominal closure sutures and wound infection. Surgery 2009;145(3):330-4.

[26] Justinger C, Schuld J, Sperling J, et al. Triclosan-coated sutures reduce wound infections after hepatobiliary surgery-a prospective non-randomized clinical pathway driven study. Langenbecks Arch Surg 2011;396(6):845-50.

[27] Ueno M, Saito W, Yamagata M, et al. Triclosan-coated sutures reduce wound infections after spinal surgery: a retrospective, nonrandomized, clinical study. Spine J 2015;15(5):933-938.

[28] Jung KH, Oh SJ, Choi KK, et al. Effect of triclosan-coated sutures on surgical site infection after gastric cancer surgery via midline laparotomy. Ann Surg Treat Res 2014;87(6):311-8.

[29] Laas E, Poilroux C, Bézu C, et al. Antibacterial-coated suture in reducing surgical site infection in breast surgery: a prospective study. Int J Breast Cancer 2012;2012:819578.

[30] Justinger C, Slotta JE, Schilling MK. Incisional hernia after abdominal closure with slowly absorbable versus fast absorbable, antibacterial-coated sutures. Surgery 2012;151(3):398-403.

[31] Fleck T, Moidl R, Blacky A, et al. Triclosan-coated sutures for the reduction of sternal wound infections: economic considerations. Ann Thorac Surg 2007;84(1):232-6.

[32] Diener MK, Knebel P, Kieser M, et al. Effectiveness of triclosan-coated PDS Plus versus uncoated PDS II sutures for prevention of surgical site infection after abdominal wall closure: the randomised controlled PROUD trial. Lancet 2014;384(9938):142-52. 